\title{
EFEITOS DA AUSÊNCIA PATERNA NA APRENDIZAGEM
}

“... a imagem do mundo e a imagem de si mesmo estão independentemente sempre ligadas" (CASTORIADIS, 1982, p. 180).

\section{RESUMO}

O texto parte de uma situação de ensino envolvendo gênero dos substantivos como modo de abordar outra compreensão do erro no processo de aprendizagem. Sugere como abordagem as significações imaginárias presentes na sociedade ao verificar como a resposta do aluno pode indicar para um ponto significativo na estrutura do sujeito que no caso apresentado poderia ter relação com a ausência paterna. Após, com a intenção de ampliar a discussão sobre as conseqüências da ausência do pai é apresentado uma síntese das dissertações e teses cadastradas no CAPES cuja categoria envolve paternidade.

\section{PALAVRAS-CHAVE}

Paternidade; Erro; Aprendizagem; Significações imaginárias

\section{EFFECTS OF PATERNAL ABSENCE IN THE LEARNING}

\begin{abstract}
This work has been originated on a learning experience involving the nouns gender as a way of achieving another understanding of the errors on the learning process. It suggests to approach the imaginary significations which are present in the context, cheking how the students answer can show a significant point in the structure of the subject that, in this case, could be related to fathers absence. After this, with the intention of amplifying the discussion about the consequences of this absence, we present a synthesis of essays and thesis, which are registered at CAPES in the category involving fatherhood.
\end{abstract}

\section{KEYWORDS}

Fhaterhood; Error; Learning; Imaginary significations

\section{EFECTOS DE LA AUSENCIA PATERNA EN EL APRENDIZAJE}

\section{RESUMEN}

El texto parte de una situación de aprendizaje que envuelve el género de los sustantivos como forma de abordar otra compresión del error en el proceso de aprendizaje. Sugiere como abordaje las significaciones imaginarias presentes en la sociedad, al verificar como la respuesta del alumno puede señalar un punto significante en la estructura del sujeto que, en el caso presentado, habría que tener relación con la intención de ampliar la discusión sobre las consecuencias de esta ausencia, es presentado una síntesis de las disertaciones y tesis catastradas en el CAPES, cuya categoría envuelve paternidad.

\section{PALABRAS CLAVES}

Paternidad; Error; Aprendizaje; Significaciones imaginarias 
Este texto apresenta de que modo a ausência da figura paterna - repercute na socialização do indivíduo principalmente no âmbito escolar. Para abordar essa temática a autora esboça um exemplo de situação de aprendizagem na qual a resposta errada pode ser tomada como um eixo de problematização e construção de novos conhecimentos. Bagno (2001) sugere no que tange à língua portuguesa que é necessário identificar, pesquisar explicações científicas sempre que o falante da língua usar $\mathrm{X}$ onde se esperaria Y. Sustenta sua proposta em Spinoza o qual, segundo seus escritos, procurava não rir das ações humanas, mas entendê-las. Em seu livro: A língua de Eulália, Bagno ( 2002) ilustra de que modo o português não padrão está relacionado às questões sociológicas, históricas ou psicológicas.

Numa aula de Português, a professora Graziela corrigia exercícios que envolviam ao mesmo tempo, a transformação do número e do gênero dos substantivos. Como a aluna Jéssica não estava acompanhando a correção no mesmo ritmo dos colegas e da professora, foi interrogada pela pesquisadora:

- Você sabe o que é masculino e feminino?

- Não.

- Mas o que você pensa sobre o que é masculino e feminino?

- Masculino é mulher, feminino é homem.

- Por que você pensa assim?

- Não sei.

- Coelho é o quê?

- Feminino.

- E coelha?

- Feminina.

- Evaca?

- Feminina.

- E boi?

- Feminino.

$-\ldots$

- E o que é ser masculino? Jéssica não respondeu, depois falou que não sabia.

Este relato é um exemplo de uma experiência de aprendizagem em que a criança utiliza-se da sua lógica para as respostas. O que intriga é o fato dessa criança não utilizar a expressão masculino para diferenciar substantivos, mesmo que a professora tivesse feito exaustivas explicações e, quando utilizou por uma única vez, relacionou à mulher. A menina 
não possuía o nome do pai na certidão de nascimento. Embora este morasse num bairro próximo, a criança só o conheceu quando já estava com 8 anos de idade. Segundo a mãe ela preferiria que a criança não tivesse contato com o pai, por ter condições de sustentar a casa sem precisar de homem para isso.

Diante desse relato optou-se por abordar duas questões:

A primeira: Como entender os erros dos alunos como representações do seu mundo vivido e por conseqüência da vida social? Anterior a essa reflexão seria a necessidade de contextualizar como os erros e a própria avaliação tem sido considerada historicamente no âmbito escolar. Contudo, como não é o eixo norteador desse trabalho convém citar os estudos de Esteban (2001), Enguita (1989), Patto (1991) (2005), Hoffman ( 1998),entre outros.

No entendimento de Esteban (2001), o professor transforma sua análise sobre o erro quando se aproxima da lógica do aluno $\mathrm{O}$ processo de mediação implica numa postura interrogativa do educador ao procurar compreender o que levou o sujeito a responder de um modo diferente do que era esperado pelo professor.

E é precisamente nesse ponto que este estudo ressalta o aspecto social do erro, quando tomado como representação das significações imaginárias do aluno e da sociedade. Para além da objetividade do conhecimento, o erro pontua a subjetividade do indivíduo e as subjetivações da sociedade.

No caso do conhecimento relativo ao gênero dos substantivos a resposta errada indicou o que foi internalizado socialmente de modo fragmentado. $\mathrm{O}$ erro referente a este conteúdo pode querer indicar uma representação da questão que se coloca para toda a sociedade: o que significa ser homem, e ser mulher. Segundo Grossi (1992) pensar em gênero:

“é pensar em masculino e feminino como constituídos a partir das relações sociais fundadas nas diferenças entre sexo - diferenças lentamente construídas e hierarquicamente constituídas. E a escola é um espaço privilegiado para este exercício, pois é nele que se dá grande parte do processo ou socialização das meninas e meninos.” (GROSSI, 1992, p. 76). 
É na escola que os alunos se socializam, sem deixar, contudo, de re-apresentar seus conflitos e fantasias. Exteriorizam seu mundo próprio tanto no modo como se relacionam, como pela sua produção escrita, oral, artística...

A segunda questão que se pode formular sobre o erro da Jéssica diz respeito a negação em utilizar o termo masculino com a ausência da figura masculina em sua vida - no caso - o pai. Neste caso, não estaria a resposta da aluna revelando uma demanda com relação à figura paterna? Na escola em que esta criança estudava $\mathbf{5 \%}$ dos alunos das séries iniciais não tinham o nome do pai registrado na ficha de matrícula. Em outra foi verificado que a ausência do registro paterno era de 11\%.

A ausência da figura paterna ocorre de modo especial nos casos em que a mulher é a chefe da família ${ }^{1}$. O DIEESE (2005) com base no PNAD (Pesquisa Nacional por Amostra de Domicílios) descreve quatro tipos de organização familiar: a nuclear, chefia com filhos; nuclear, chefia sem filhos; a monoparental e a unipessoal. A "nuclear" comporta a presença de um chefe e seu cônjuge. A monoparental envolve apenas a presença do chefe, sem cônjuge, com ou sem filhos, mas com outros membros, como pais ou irmãos. As unipessoais dizem respeito à presença apenas do chefe (ou seja, de uma única pessoa). No intervalo de tempo situado entre os anos de 1993 e 2003, das famílias monoparentais, 18,1\% eram chefiadas por mulheres e apenas 2,2\% tiveram como responsáveis os homens.

Conforme o PNAD 2006 fornecido pelo Instituto Brasileiro de Geografia e Estatística - ( IBGE base 2004), de um total de 71,7\% dos lares brasileiros chefiados por homens, em 94,5\% existe a presença do cônjuge e 5,52 não. Entretanto, a situação se inverte nos lares brasileiros chefiados por mulheres (28,3\%), pois em apenas 18,5\% existe a presença do cônjuge, enquanto 81,5\%, não.

Estes dados retratam, globalmente, os relatos cotidianos de outras mães quando afirmam que não precisam de homem em casa e que elas poderiam criar seus próprios filhos. Entretanto, o que se constata, na maior parte das famílias monoparentais, é que a ausência da figura masculina é sentida e vivida tanta pelas mulheres como pelos filhos. No caso destes

\footnotetext{
${ }^{1}$ Um dos estudos referentes aos novos arranjos familiares ocupando-se das mulheres como chefes de famílias é ode Perruchi e Beirão (2007).
}

(C) ETD - Educação Temática Digital, Campinas, v.10, n.1, p.87-104, dez. 2008 - ISSN: 1676-2592. 
últimos, em alguns casos, percebe-se até mesmo um precoce amadurecimento da criança no sentido de assumir responsabilidades na casa. Já outros revelam situações de indisciplina, evasão escolar, excesso de faltas escolares ou ainda baixo desempenho escolar. O que não significa que, necessariamente a ausência do pai bem como pais separados ocasionaria dificuldade na aprendizagem, pois do que se trata é de uma referência para a criança. Referência que pode ser em muitos casos a própria mãe.

A fim de compreender melhor o problema da ausência do nome do pai na certidão de nascimento ou ficha de matrícula do aluno se faz necessário historiar como o lugar do pai foi se delineando no grupo familiar. Este tipo de agrupamento faz parte das muitas invenções sociais e históricas criadas para conferir certa organização à sociedade humana. Uma destas centrada na figura masculina de modelo patriarcal está amplamente apresentada nos Cinco Livros de Moisés. Narvaz \& Koller (2006, p.50) ancoradas nos estudos antropológicos de Engels (1884-1984) e Muraro (1997), apontam que em outros tempos, no início da história da humanidade as sociedades eram coletivistas, tribais, nômades e matrilineares. Por serem nômades e desconhecerem a participação masculina na reprodução, organizavam-se predominantemente em torno da figura da mãe. Somente com o desenvolvimento da agricultura, aliada à descoberta do fogo, utilização da caça e fixando-se, portanto, a um território é que irá ser conhecida a função do homem na reprodução.

Engels (1884-1984) analisa os estudos da época referente à origem da família em sua relação como o modelo de família tradicional: monogâmica e patriarcal. Cita o matrimônio primitivo descrito por Mac Lennan (1886 apud ENGELS, 1984,p.42) no qual os homens se viam obrigados a buscar parceiras - e as mulheres, parceiros - fora do grupo nomeando-as de raças exógamas. Era nestas que o vínculo de sangue se realizava pelo lado materno. Por endógamas intitulou os povos, segundo os quais os homens de determinado grupo deveriam procurar suas esposas circunscritas ao seu próprio grupo.

Embora Mac Lennan reconheça como forma de matrimônio apenas a poligamia, a poliandria e a monogamia, Lubbock (1870 apud ENGELS,1984, p. 45), segundo Engels, evidenciou outro modo que será o matrimônio por grupos nos quais vários homens tinham em comum várias mulheres. Engels segue a discussão estendendo-se nos sistemas de famílias descritas por Morgan (1871 apud ENGELS,1984, p.63) como consangüíneas, punaluas, 
sindiásmicas e monogâmicas. A família consangüínea representou um primeiro progresso da família, pois embora todos fossem maridos e mulheres uns dos outros (seja entre irmãos e irmãs, primos e primas) excluíam-se os pais e filhos, havendo, portanto, uma primeira interdição para o incesto. Por outro lado, a família punalua vem a ser um segundo progresso de organização da família, ao excluir os irmãos. Finalmente, na família sindiásmica o homem terá uma mulher principal (o que não significa que seja a favorita) entre as outras e o mesmo sucede com a mulher. A monogamia será resultante da propriedade privada ao garantir-se herança aos filhos legítimos. É quando se estabelece o patriarcado como uma nova ordem social centrada na descendência patrilinear cujo controle do corpo, da sexualidade da mulher passa a ser realizada pelos homens.

Segundo Saffioti (1979), no Brasil, a história da instituição familiar adotou o modelo patriarcal seja por ser conhecido pelos colonizadores, seja por ser adaptado na época, às condições sociais do Brasil de latifúndio e escravatura. Chauí (1989) afirma que mesmo após a desintegração do patriarcado rural nas diversas regiões do Brasil, esta mentalidade permaneceu na vida e na política brasileira por meio do coronelismo, do clientelismo e do protecionismo. D’Ávila Neto (1994), por sua vez, constata que mesmo no meio urbano, a origem das atitudes autoritárias sobre a condição feminina deve-se aos esquemas de dominação social que caracterizaram o patriarcado tradicional brasileiro.

Narvaz \& Koller (2006) citam os direitos conquistados pelas mulheres nas primeiras décadas do século XX visando aumentar sua participação na vida pública. Foi assim que em 1916, o Código Civil Brasileiro, vislumbrando um germe de autonomia, fez constar que a mulher casada poderia trabalhar, porém, ainda segundo o modelo patriarcal , no qual isto só poderia acontecer com a autorização do marido. Essa imposição só foi alterada em 1962 quando o Código Civil Brasileiro sofreu alterações permitindo à mulher trabalhar sem precisar da autorização do cônjuge. Outra conquista se efetivou em 1934, quando Getúlio Vargas, em seu governo provisório, assegurou em nova constituição, o voto da mulher. E somente em 1941, o trabalho feminino foi regulamentado pela Consolidação das Leis Trabalhistas. Movimentos feministas foram reprimidos ao longo da ditadura Vargas, sendo restabelecidos novamente no início da Segunda Guerra Mundial. Em 2002, um novo Código Civil substituindo os anteriores, consolidou pela Constituição Federal de 1988, alguns direitos femininos já existentes na sociedade. Um dos aspectos refere-se à destituição do modelo de 
família regido desde os tempos feudais pelo pátrio poder (poder do pai ${ }^{2}$ ), pelo pater familiae, o qual pressupõe a igualdade de poder entre os membros do casal. Como representação desta nova visão a linguagem androcêntrica do código alterou alguns termos, substituindo "todo homem", por "toda pessoa". Mesmo a Constituição Federal Brasileira, de 1988, no art. 226, § $5^{\circ}$ Constituição, estabelece que "os direitos e deveres referentes à sociedade conjugal são exercidos igualmente pelo homem e pela mulher" (BRASIL, 1988, p.147).

Se a legislação assegura direitos e deveres iguais, com o mesmo compromisso na educação dos filhos, na prática isso não ocorre. Configuram-se novos arranjos familiares, que resultam em novas realidades, justamente quando um dos procriadores é ausente, isentando-se da responsabilidade familiar.

Como, na maior parte das famílias brasileiras, as primeiras referências para o filho são os pais e como o índice de famílias monoparentais tem aumentado em torno de $32 \%{ }^{3}$ nos últimos anos, torna-se necessário olhar com mais atenção os efeitos desta nova configuração familiar.

Existem alguns estudos que abordam a ausência da figura paterna, dentre eles pode-se citar o de Muza (1998, citada por EIZIRIK \& BERGMANN, 2004).

Em suas pesquisas, Muza ( apud Eizirik, M. \& Bergmann, 2004, p.3), constatou que, crianças com pais ausentes acabaram tendo problemas de identificação sexual, dificuldades em reconhecer limites e em assimilar regras de convivência social. Por extensão surgiu a dificuldade de internalizarão de um pai simbólico, capaz de representar a instância moral do indivíduo.

Outro trabalho significativo igualmente abordado por Eizirik \& Bergmann (2004) são os de Paschall, et al (2003 apud Eizirik; Bergmann, 2004, p.332) ao focarem os efeitos de

\footnotetext{
2 "Cabe destacar que o patriarcado não designa o poder do pai, mas o poder dos homens, ou do masculino, enquanto categoria social. O patriarcado é uma forma de organização social na qual as relações são regidas por dois princípios básicos: 1) as mulheres estão hierarquicamente subordinadas aos homens e, 2) os jovens estão hierarquicamente subordinados aos homens mais velhos”. (NARVAZ; KOLLER, 2006)

${ }^{3}$ Segundo o PNAD (Pesquisa Nacional por Amostra de Domicílios) realizado pelo IBGE a chefia feminina sem cônjuge passou de 19,3\% para 25,5\% em questão de dez anos, mais precisamente de 1992 para 2002. (DIEESE, 2004, p. 01).
}

(c) ETD - Educação Temática Digital, Campinas, v.10, n.1, p.87-104, dez. 2008 - ISSN: 1676-2592. 
ausência paterna diretamente em adolescentes afro-americanos que apresentavam comportamento delinqüente. O trabalho concluiu que os achados dos estudos relacionados ao tema são mistos e inconclusivos e que há grande preocupação a respeito da ausência paterna, em famílias afro-americanas, em especial ao efeito negativo que isso pode causar no desenvolvimento desses alunos. Segundo os autores, a ausência paterna não estaria associada ao comportamento delinqüente dos filhos. Por outro lado, puderam constatar que o efeito negativo do fator socioeconômico no comportamento delinqüente foi percebido com mais freqüência em famílias que apresentavam ausência paterna.

Já Eizirik e Bergmann (2004) discutem a influência da ausência paterna no desenvolvimento da criança e do adolescente, em especial relacionados aos aspectos cognitivos e comportamentais. As autoras realizam uma revisão teórica sobre o assunto e após apresentam um estudo de caso de um aluno com mau desempenho escolar. Por meio do fragmento de uma sessão de análise na qual a criança reclama da ausência paterna, as autoras discutem com muita propriedade a repercussão desse fato na vida escolar da criança.

Tendo em vista uma análise mais global dos estudos realizados no Brasil, realizou-se uma investigação nos resumos divulgados no site da Coordenação de Aperfeiçoamento de Pessoal de Nível Superior- CAPES-, tendo por categoria o termo “paternidade”. Constatou-se que existiam 160 dissertações/teses registradas na CAPES, até o primeiro trimestre do ano de 2006 na área de Ciências Sociais Aplicadas ou Ciências Humanas. Destas, fez-se a seguinte classificação, conforme o quadro abaixo:

Tabela n.1

Categoria: Paternidade

\begin{tabular}{|l|l|l|}
\hline Classificação deste Estudo & Teses (doutorado) & \% \\
\hline Humanas & 21 & 13,12 \\
\hline Ciências da Saúde & 86 & 53,70 \\
\hline Ciências Jurídicas & 10 & 06,25 \\
\hline Psicologia/Psicanálise & 42 & 26,25 \\
\hline Ciências Exatas & 01 & 00,60 \\
\hline Total & 160 & $99,92 \ldots$ \\
\hline
\end{tabular}

Fonte: CAPES/2006

Teses: Ciências Sociais Aplicadas ou Ciências Humanas 
Embora as Ciências Jurídicas e a Psicologia façam parte das Ciências Sociais Aplicadas e Ciências Humanas, conforme distribuição da base de dados das áreas de conhecimento da CAPES, foi necessário verificar e diferenciar quantos estudos já foram produzidos, em especial na Psicologia e nas Ciências Jurídicas. Dentre os estudos destacam-se os trabalhos de:

Thurler (2004), em que analisa a alta incidência de crianças brasileiras sem reconhecimento paterno em seus registros, o que para a autora é um fenômeno ainda não acompanhado pelo País. Este é um todo que espelha uma situação sociológica envolvendo questões políticas de cidadania e de relações sociais de gênero, implicadas na deserção da paternidade. Segundo a pesquisadora, no Brasil uma em cada três crianças anualmente nascidas possui, em seus registros, somente filiação materna. Esta deserção paterna não adviria apenas de problemas administrativos, e sim, de um fenômeno socialmente construído, por via histórica, política e jurídica. Salienta que as intervenções do Ministério Público e algumas decisões muito recentes do Judiciário sinalizam um movimento do Estado brasileiro de uma situação de apatia para uma condição de protagonismo em relação à paternidade desertora. Conclui que a paternidade e a parentalidade no masculino, conforme compreendidas nesta tese, envolvem relações sociais de geração, do homem-pai com a criança-filha, desafiando o pai-cidadão ao exercício do compromisso, e relações sociais de sexo, do homem-pai com a mulher-mãe, provocando o pai-cidadão ao exercício da solidariedade. A autora enfoca um dos aspectos desta situação constrangedora ao revelar a situação das mulheres silenciadas pela perversão do poder patriarcal.

Outros estudos sobre esse tema são os de Vizzoto (1988) e Santos (2004) ao sinalizarem algumas das conseqüências diante da ausência paterna. Vizzoto (1988) aproximase das conclusões de Eizirik \& Bergmann (2004) na medida em que constata a repercussão da ausência paterna no baixo aproveitamento escolar das crianças. Por outro lado, Santos (2004), ao preocupar-se com os efeitos escolheu como sujeitos os adultos cujas infâncias foram marcadas pela falta da figura do pai. O pesquisador concluiu que essa demanda não repercutiu negativamente no sujeito que utilizou outros substitutivos significativos. 
Vizzotto (1988) se propôs a verificar a variável ausência paterna e seus correlatos na psicodinâmica e no aproveitamento escolar da criança. Foram selecionadas 14 crianças, com idade entre oito anos e meio a nove anos e meio, em duas escolas estaduais do interior do estado de São Paulo. O estudo foi feito envolvendo amostras em quatro grupos, os quais tiveram por critério a presença ou ausência do pai no lar e o baixo ou alto aproveitamento escolar. Vizzotto concluiu que a ausência paterna prejudica o aprendizado na medida em que traz danos ao desenvolvimento psicodinâmico pelas dificuldades da criança em não ter a figura masculina como fonte de identificação para desprendimento narcísico primário com a mãe acarretando na elaboração de símbolos. Além disso, a presença paterna favorece a psicodinâmica e o aprendizado na medida em que a presença interna significa uma presença psicológica e não meramente física.

Santos (2004) discute com base na psicologia existencial o significado da ausência paterna para adultos. Para tanto, realizou uma entrevista aberta com cinco sujeitos adultos, sendo três do sexo feminino, e dois do sexo masculino. A análise dos dados foi feita segundo os critérios da pesquisa fenomenológica sendo levantados os seguintes temas invariantes: a falta de um pai, a relação com a mãe, as figuras substitutas, a relação com o sexo oposto e o enfrentamento. Esses temas foram discutidos segundo o referencial teórico da Psicologia Existencial Fenomenológico. Concluiu que mais do que propriamente a relação com o pai em seu aspecto eminentemente formal torna-se importante a qualidade de relações que a pessoa estabelece com os outros significativos e com a cultura como um todo.

Outra via relacionada à paternidade são os estudos de Fontes (2004), Rodrigues (2004), Bezerril (2001) e Barros (1999) os quais abordam a metáfora da função paterna do ponto de vista psicanalítico bem como os efeitos no desenvolvimento educacional quando o limite e a Lei se tornam inexistentes na família. Fontes conclui sobre o fracasso da transmissão o qual se aproxima de Barros ao relacionar esse fracasso diante das normas sociais e do ordenamento jurídico. Já Rodrigues (2004) e Bezerril (2004) aproximam-se quanto às conclusões ao verificar a dificuldade de aprender ou a debilidade enquanto sintoma.

Note-se que Fontes, (2004) discorre sobre o fracasso escolar, a partir dos conceitos, em especial o de Nome-do-Pai, termo utilizado por Lacan. Salienta que o declínio 
da função paterna está associado ao desenvolvimento da ciência, iniciado junto com a era moderna. Conclui que estamos convivendo com um tipo de fracasso característico de nossa época: o fracasso da transmissão.

Observa-se que Rodrigues (2004) adota como referencial teórico a psicanálise freudiana e realiza o estudo de caso de uma criança de oito anos, com dificuldades para aprender. Na análise do caso, foi possível investigar as implicações da autoridade paterna no processo de apropriação de conhecimentos da paciente, especialmente da linguagem e do raciocínio matemático, além da intolerância à frustração. $\mathrm{O}$ autor do estudo conclui que a autoridade paterna, dependendo da maneira como é exercida, acrescida de outros fatores, pode levar a entraves no desenvolvimento da capacidade de aprendizagem.

Merece destaque os estudos de Bezerril (2001) e de Barros (1999) ao relacionar os sintomas sociais com o desejo materno visto que do ponto de vista psicanalítico é a mãe quem funda o pai na vida do filho ao desviar seu olhar do filho para o homem.

Vale ressaltar que Bezerril (2001) explica a debilidade (sem qualquer comprometimento orgânico) à luz da Psicanálise, como uma resposta da criança diante do desejo materno, quando de sua constituição como sujeito. Trata-se de um estudo teórico sobre a dificuldade do sujeito em posicionar-se ante o Outro quando tem que fazer uma escolha frente ao desejo materno. O autor apresenta alguns casos clínicos em que analisa a passividade assumida pelo débil ante o saber e, propõe a indicação da psicanálise como um tratamento possível para esses casos.

A abordagem de Barros (1999) analisa o percurso histórico do conceito de paternidade dentro do Ordenamento Jurídico, e seus prováveis efeitos na organização familiar da atualidade. Essa pesquisadora concebe como campo de pesquisa bibliográfica, as teorias sobre o Ordenamento Jurídico, os documentos legislativos e os pressupostos da teoria psicanalítica, além de constatar que o Direito revela-se impotente diante do desejo materno. É a mãe quem funda o pai para seu filho, passando pelo seu consentimento a entrada ou não do terceiro que o pai representa. O desacordo entre o desejo materno e a palavra do pai, transcrito nas páginas processuais dos casos estudados, cria na criança uma série de sintomas sociais. 
Um desses sintomas sociais que Barros (2005) aponta, discretamente, em seu livro e que se constata no cotidiano escolar diz respeito às dificuldades de aprendizagem.

Nas entrevistas individuais, e nos grupos focais com os responsáveis percebe-se as inúmeras artimanhas familiares que imobilizam a criança perante o seu desejo, inclusive de crescer, de aprender. O pai não exerce seu papel nem mesmo como homem desejado por sua mulher, enquanto que a mãe passa a assumir de modo excessivo a função materna e deixa de se ver como mulher. Por conseqüência, esta mãe que vive toda para o filho acaba por sufocálo ao evitar experiências nas quais a criança possa se frustrar.

Se esta asfixia ocorre nas famílias de constituição nuclear, em alguns casos, nas famílias monoparentais, em que o pai se omitiu ou está excluído do universo familiar, essa situação se amplia, principalmente quando em vez do seu nome existe o vazio...

Nos grupos focais com a participação de pais de alunos que não se alfabetizaram, pode-se perceber vários relatos em que a mãe assumiu o papel de única provedora. Casos em que as mães ofertavam vários tipos de brinquedos e roupas. Outras, não permitiam que a criança brincasse com colegas, ou ainda situações nas quais perpetuavam o estado de infantilização estimulando o uso de bicos e mamadeiras, impedindo o filho/a de fazer suas próprias escolhas, seja para vestir-se, ou se alimentar. Resumindo, é como se essa mãe fizesse um movimento para que o filho voltasse para o cordão umbilical e se tornasse somente dela. Já não haveria distinção, como numa relação complexa que é a de marido e mulher.

Segundo Castoriadis (1982), entre a mãe e o filho recém-nascido existe a fase monádica, que é compreendida como um estado de indistinção, de alienação, no qual o sujeito é apenas um elemento subordinado à direção dada por outrem, ou seja, ao desejo da mãe. Nessa fase, tanto o sujeito que tem fome como o que tem o "seio" para saciá-la são uma mesma pessoa, pois ambos estão indivisos. Um deseja o seu objeto (no caso, o seio da mãe), o outro faz do sujeito que tem fome seu próprio objeto de desejo. O momento da ruptura monádica ocorre com a negação do "seio”; é só por essa via que ambos se constituirão como sujeitos reais: o infans só poderá constituir-se um outro, projetando nele seu próprio esquema imaginário de onipotência (CASTORIADIS, 1982, p. 348), ou seja, como alguém capaz de preencher esse abismo. 
Por isso, para Castoriadis (1987, p. 225), o ser é Caos, ou Abismo ou o SemFundo. O sujeito segue sua existência preenchendo o Caos com significações imaginárias sociais, como que procurando voltar ao estado primário, da indistinção. E desta significação ninguém é senhor. É preciso e basta que o outro possa significar para a criança que ninguém, entre todos aqueles que ela poderia encontrar, é fonte e senhor absoluto da significação, ou seja, a significação não depende de nenhuma pessoa particular. Acrescenta ainda que, o pai, não é pai se ele mesmo não se liga à sociedade e a sua instituição.

Concentrando-se no questionamento sobre o que é ser pai, Castoriadis (1987) diz haver um desgaste de valores, que se apresenta na família pelo "vazio do discurso do pai com a mãe. Ocorre um desgaste da experiência de realidade para as crianças: não há mais nada de rijo contra que chocar-se, não se deve privá-las, frustrá-las, entristecê-las, é preciso sempre compreendê-las” (CASTORIADIS, 1987, p. 99).

É como se a lei não servisse mais de obstáculo à experiência do gozo, bastando dar livre curso à expressão da criança, completa o autor.

A liberdade ao gozo está presente de diversos modos na escola e na sociedade desde uma dificuldade de aprendizagem passando por atitudes delinqüentes que se estendem à corrupção no meio social, demonstrando com isso que a história do indivíduo e da sociedade estão sempre ligadas. Desse modo, tem-se como princípio a instância da política como eixo civilizatório, porém o exercício da política só é possível pela autonomia. Autonomia que exige uma ruptura com a mônada psíquica provocada pela mãe. Como lembra Barros, é a mãe quem funda o pai para a criança.

A figura da mãe se apresenta com um corpo feminino ao convocar a presença de um outro. Destituindo-se de uma soberania institui a socialização no ser humano ao desviar seu olhar do filho para o pai: “ ... o outro ( a mãe) destitui-se de sua onipotência preferindo-se a um terceiro, ao mesmo tempo em que significa 'à criança que seu próprio desejo tem um outro objeto fora dele, e que ela própria é objeto do desejo de um outro, o pai “ (CASTORIADIS, 1982, p. 353). 
O pai, por outra via, irá mediar a relação da criança com a sociedade, fazendo com que a mesma se ligue ao mundo, bata as asas e alce vôo.

\section{À GUISA DE CONCLUSÃO}

Retomando o exemplo de Jéssica pode-se extrair dos seus erros outra referência de compreensão da aprendizagem cuja lógica consista no conhecimento em sua relação com a subjetividade (história social do indivíduo) e os processos de subjetivação (ideologias). Tomando esse princípio como uma das vias das representações escolares é bem provável que um erro de aluno não se restrinja às explicações de cunho unicamente individual. O erro poderá servir como pista do que se passa num sujeito e de modo mais amplo numa sociedade. No caso de Jéssica, a resistência em assimilar o termo masculino (enquanto termo que marca uma diferença com a sua própria sexualidade) para representar substantivos masculinos pode (ou não) ter a ver com a ausência da figura paterna na sua vida. A insistência na expressão feminino ( termo que marca a semelhança entre Jéssica e sua mãe) lembra a relação monádica enfatizada por Castoriadis ou o desejo materno salientado por Barros e Bezerril. Ou seja, é a mãe quem funda a convivência com o diferente. O que não isenta a responsabilidade do pai enquanto desejante de um filho e de uma filha. Essa relação do pai com o filho/filha, lembra as conclusões de Thurler quando relaciona a ausência do nome do pai na certidão de nascimento às questões de gênero visto que as relações sociais de geração podem se perpetuar marcando a dificuldade do homem-pai com a criança-filha e mesmo do homem-pai com a mulher mãe.

E, para além de um pai e de uma mãe, pode-se dizer a respeito das Jéssicas que habitam as moradas de todos os que se aventuram ao ato de conhecer que um sujeito só irá aprender se desejar emancipar-se, se quiser desprender-se da saia da mãe para crescer. Ou seja, constituir-se como ser social o que implica em aceitar o outro- o diferente. 


\section{REFERÊNCIAS}

BAGNO, M. A língua de Eulália: novela sociolingüística. 11. ed. São Paulo: Contexto, 2001.215p.

2002.149p.

Preconceito lingüístico: o que é. Como se faz. São Paulo: Edições Loyola,

BARROS. F. O. Do Direito ao pai : sobre a paternidade no ordenamento jurídico. 1999. 111 fl. Dissertação (Mestrado em Psicologia) - Universidade Federal de Minas Gerais, Minas Gerais, 1999. v.1. Disponível em: <http://servicos.capes.gov.br/>. Acesso em: 15 fev. 2006.

Rey, 2005. 127p.

Do Direito ao pai: a paternidade no tribunal e na vida. 2. ed. Belo Horizonte: Del

BEZERRIL, S. M. T. Não posso cantar e assobiar ao mesmo tempo: o débil e sua escolha ante o saber. 2001. 98 fl. Dissertação. (Mestrado em Psicologia). Universidade Federal do Rio de Janeiro, Rio de Janeiro, 2001. v.1. Disponível em: http://servicos.capes.gov.br>/. Acesso em: 15 fev. 2006.

BRASIL. Constituição [da] República Federativa do Brasil. Brasília: Senado Federal, 1988.

CAPES.Portal de Periódicos. Disponível em: http://www.capes.gov.br/. Acesso em 15 fev. 2006.

CASTORIADIS, C. A instituição imaginária da sociedade. 3. ed. Rio de Janeiro: Paz e Terra, 1982. 418p. 1987. 466p.

As encruzilhadas do labirinto II: domínios do homem. Rio de Janeiro: Paz e Terra,

CHAUÍ, M. Conformismo e resistência: aspectos da cultura popular no Brasil. 4. ed. São Paulo: Brasiliense, 1989. 179p.

D’AVILA NETO, M. I. O autoritarismo e a mulher: o jogo de dominação macho-fêmea no Brasil. Rio de Janeiro: Artes e Contos, 1994. 132p.

DEPARTEMENTO INTERSINDICAL DE ESTATÍSTICAS E ESTUDOS SÓCIOECONÔMICOS - DIEESE. Trabalho e renda da mulher na família. Estudos e Pesquisas, ano I, n.6, mar. de 2005. Disponível em:

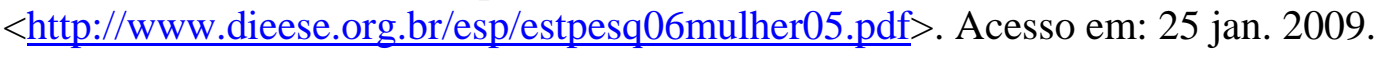


EIZIRIK, M.; BERGMANN, D. S. Ausência paterna e sua repercussão no desenvolvimento da criança e do adolescente: um relato de caso. Revista de Psiquiatria. Porto Alegre, v. 26 n. 3, p.330-336 Set./Dec. 2004. Disponível em: <http://www.revistapsiqrs.org.br/> Acesso em: 20 fev. 2006.

ENGELS, F. A origem da família, da propriedade privada e do estado. 5. ed. Tradução de José Silveira Paes. São Paulo: Global, 1984.215p.

ESTEBAN, M. T. O que sabe que erra? Reflexões sobre a avaliação e o fracasso escolar. Rio de Janeiro: DP\&A, 2001. 198p.

ENGUITA, F. M. A face oculta da escola: educação e trabalho no capitalismo. Porto Alegre: Artes Médicas, 1989.252p.

FONTES. A . M. M. Fracasso escolar: sintoma da modernidade. 2004. 170 fl. Tese.

(Doutorado em Psicologia Escolar e do Desenvolvimento Humano) - Universidade de São Paulo, São Paulo, 2004. v.1. Disponível em: http://servicos.capes.gov.br/. Acesso em: 15 fev. 2006.

GROSSI, M. P. O Masculino e o feminino na educação. Paixão de Aprender, Porto Alegre, n.4, set. 1992, p.68-77.

HOFFMANN, J. Avaliação mediadora: uma prática em construção da pré-escola à universidade. 14. ed. Porto Alegre: Mediação, 1998. 198p.

INSTITUTO BRASILEIRO DE GEOGRAFIA E ESTATÍSTICAS - IBGE. PNAD 2005. Informação Demográfica e Socioeconômica. Estudos e Pesquisas, Rio de Janeiro, n. 19, 2006. Disponível em: <http://www.ibge.gov.br/> Acesso em 25 jan/2009.

MURARO, R.M. A mulher no terceiro milênio: uma história da mulher através dos tempos e suas perspectivas para o futuro. 4. ed. Rio de Janeiro: Record; Rosa dos Tempos, 1997. 205p.

NARVAZ, M. G.; KOLLER, S. H. Famílias e patriarcado: da prescrição normativa à subversão criativa. Revista Psicologia \& Sociedade, Porto Alegre, v.18, n.1, jan./abr. 2006. p.49-55

ORLANDI, E. P. Análise de Discurso: princípios e procedimentos. Campinas: Pontes, 2000. 100p.

PATTO, M.H.S. Introdução à psicologia escolar. São Paulo: T. A. Queiroz, 1991. 430p.

Exercícios de indignação: escritos de educação e psicologia. São Paulo: Casa do Psicólogo, 2005. 189p. 
PERUCHI J.; BEIRÃO, A M. Novos arranjos familiares: Paternidade, parentalidade e relações de gênero sob o olhar das mulheres chefes de família. Psicologia Clinica, n.19(2), 2007, p.57-69.

RODRIGUES, A. L. F. P. Os entraves da autoridade paterna no processo de aprendizagem: uma abordagem psicanalítica. 2004. 92 fl. Dissertação.(Mestrado em Psicologia) - Universidade São Marcos. 2004. v.1. Disponível em:

<http://servicos.capes.gov.br/> Acesso em: 15 fev. 2006.

SAFFIOTI, H. A mulher na sociedade de classes: mitos e realidade. Rio de Janeiro: Rocco, 1979. 384p.

. Contribuições feministas para o estudo da violência de gênero. Cadernos Pagu, Campinas, n. 16, 2001, p.115-136.

SANTOS, G. A . O. O Significado da Ausência Paterna para Adultos: um estudo fenomenológico. 2004. 128p. Dissertação (Mestrado em Psicologia) - Pontifícia Universidade Católica de Campinas, Campinas, 2004. v.1. Disponível em:

$<$ http://servicos.capes.gov.br/>. Acesso em: 15 fev. 2006.

THURLER, A. L.. Paternidade e Deserção: crianças sem reconhecimento, maternidades penalizadas pelo sexismo. 2004. 303fl. Tese (Doutorado em Sociologia) - Universidade de Brasília, Brasília, 2004. v.1. Disponível em: < http://servicos.capes.gov.br/>. Acesso em: 15 fev. 2006.

VIZZOTTO, M. M. Ausência Paterna e suas Associações a Psicodinâmica e ao Aproveitamento Escolar da Criança. 1988. 203 fl. Dissertação (Mestrado em Psicologia) Pontifícia Universidade Católica de Campinas, Campinas, 1988. v.1. Disponível em: <http://servicos.capes.gov.br/>. Acesso em: 15 fev 2006. 
